\title{
BMJ
}

\section{Effects of a physiotherapy and occupational therapy intervention on mobility and activity in care home residents: a cluster randomised controlled trial}

\author{
Catherine M Sackley, professor of physiotherapy research, Maayken E van den Berg, research \\ physiotherapist, Karen Lett, research occupational therapist, Smitaa Patel, statistician, Kristen Hollands, \\ project coordinator, Christine C Wright, senior lecturer, Thomas I Hoppitt, research fellow
}

School of Health and Population Sciences, Primary Care Clinical Sciences, University of Birmingham, Edgbaston, Birmingham B15 2TT Correspondence to: $\mathrm{T} J$ Hoppitt t.j.hoppitt@bham.ac.uk

Cite this as: BMJ 2009;339:b3123 doi:10.1136/bmj.b3123

\section{ABSTRACT}

Objective To compare the clinical effectiveness of a programme of physiotherapy and occupational therapy with standard care in care home residents who have mobility limitations and are dependent in performing activities of daily living.

Design Cluster randomised controlled trial, with random allocation at the level of care home.

Setting Care homes within the NHS South Birmingham primary care trust and the NHS Birmingham East and North primary care trust that had more than five beds and provided for people in the care categories "physical disability" and "older people."

Participants Care home residents with mobility limitations, limitations in activities of daily living (as screened by the Barthel index), and not receiving end of life care were eligible to take part in the study.

Intervention A targeted three month occupational therapy and physiotherapy programme.

Main outcome measures Scores on the Barthel index and the Rivermead mobility index.

Results 24 of 77 nursing and residential homes that catered for residents with mobility limitations and dependency for activities of daily living were selected for study: 12 were randomly allocated to the intervention arm (128 residents, mean age 86 years) and 12 to the control arm (121 residents, mean age 84 years). Participants were evaluated by independent assessors blind to study arm allocation before randomisation (0 months), three months after randomisation (at the end of the treatment period for patients who received the intervention), and again at six months after randomisation. After adjusting for home effect and baseline characteristics, no significant differences were found in mean Barthel index scores at six months post-randomisation between treatment arms (mean effect 0.08, 95\% confidence interval -1.14 to $1.30 ; \mathrm{P}=0.90$ ), across assessments $(-0.01,-0.63$ to $0.60 ; P=0.96)$, or in the interaction between assessment and intervention $(0.42,-0.48$ to 1.32; $P=0.36$ ). Similarly, no significant differences were found in the mean Rivermead mobility index scores between treatment arms $(0.62,-0.51$ to $1.76 ; \mathrm{P}=0.28)$, across assessments $(-0.15,-0.65$ to $0.35 ; \mathrm{P}=0.55)$, or interaction (0.71, -0.02 to $1.44 ; \mathrm{P}=0.06$ ).

Conclusions The three month occupational therapy and physiotherapy programme had no significant effect on mobility and independence. On the other hand, the variation in residents' functional ability, the prevalence of cognitive impairment, and the prevalence of depression were considerably higher in this sample than expected on the basis of previous work. Further research to clarify the efficacy of occupational therapy and physiotherapy is required if access to therapy services is to be recommended in this population.

Trial registration ISRCTN79859980

\section{INTRODUCTION}

In the United Kingdom, 4\% of the population over the age of 65 are resident in care homes, with this proportion increasing with age. Care homes in the UK are defined as either providing nursing care (nursing home) or not providing nursing care (residential care home). The occupants of residential care homes are, therefore, generally less dependent than those in nursing care homes, but the level of aid they require precludes them from living completely independently. Nursing homes are required to have at least one registered nurse within the staff.

Seventy five per cent of the population in nursing homes and residential care homes are severely disabled on at least one dimension of disability, with half of all residents dependent in self care tasks. It seems logical to expect that this population of frail elderly people who have mobility issues and are dependent in activities of daily living would receive rehabilitation services. Several surveys, however, have found that care home residents in the UK have limited access to rehabilitation services such as physiotherapy and occupational therapy. A 2001 study showed that only 3.3\% of elderly nursing home residents receive occupational therapy, whereas only $10 \%$ receive physiotherapy, the majority of which is privately funded. ${ }^{1}$ Physiotherapy and occupational therapy services are far more widely 
available in other countries, ${ }^{2-4}$ and are much more likely to be requested when costs are reimbursed. ${ }^{5}$

Implementing interventions that focus on behavioural change and mobility training in a frail, frequently cognitively impaired, elderly nursing home population is feasible ${ }^{6-10}$; however, interventions are difficult to maintain owing to the required treatment intensity and the cost. ${ }^{11}$ The high levels of staff knowledge and skill required to continue treatment could be absent in the UK as training opportunities are scarce for care home staff. ${ }^{12-14}$

Evidence for the benefit of rehabilitation services in this population is conflicting and inconclusive. A recent trial concluded that a programme of functional rehabilitation had minimal impact for elderly people in residential care with normal cognition and no benefit for those with poor cognition. ${ }^{15}$ Similarly, Mozley and colleagues found little or no evidence that occupational therapy reduces depression, dependency, or long term institutionalisation in elderly care home residents, ${ }^{16}$ and Mulrow and colleagues found that physiotherapy provided only modest mobility benefits in very frail long stay US nursing home residents with physical disabilities. ${ }^{17}$ In contrast, a UK study of care home residents with stroke related disability found that occupational therapy was beneficial in terms of maintaining self care independence. ${ }^{18}$ Furthermore, two relatively recent systematic reviews found evidence that physical training had positive effects on mobility, physical functioning, and cognition in institutionalised elderly patients. ${ }^{1920}$ One of these reviews, however, concludes that there is contradictory evidence for the benefits of physical training on gait and activities of daily living. ${ }^{19}$

Physiotherapy and occupational therapy could be cost effective in elderly care home residents, in that therapy costs can be outweighed by a reduction in care requirement, reduced service use costs, and a fall in hospital admission rates. ${ }^{9}$ However, two US studies found no statistically significant difference and a minor difference in cost between such interventions and routine care. ${ }^{2122}$

The main objective of this trial was to evaluate the clinical effectiveness of a programme of physiotherapy and occupational therapy against standard care in care home residents with mobility limitations who are dependent on carers in some activities of daily living.

\section{METHODS}

The register of care homes held by Birmingham City Council social services for 2004 was used to identify, within the boundaries of NHS South Birmingham and NHS Birmingham East and North primary care trusts, homes that had more than five beds and provided the care categories "physical disability" and "older people." From the register, 24 of 77 nursing and residential homes were selected that catered for residents with mobility limitations who are dependent in activities of daily living. Homes were purposely chosen to encompass variations in geographical location, size, and funding sector (table 1). Home managers were approached for consent and care homes were subsequently recruited between June 2004 and June 2005 in three phases to spread both therapist and assessor workload.

At entry of a care home to the study, care home staff were asked to screen all residents with the Barthel index of activities of daily living and to provide information on cognitive status for consent purposes. ${ }^{23}$ Residents who scored below 5 or over 16 on the Barthel index were excluded from the study on the basis that the intervention would be considered too intense or insufficient for their needs, respectively. Residents who were admitted to hospital with acute illness and those admitted to the care home for end of life care were also excluded.

Cognitively sound residents included in the study provided written informed consent. Residents with substantial cognitive impairment had consent provided by their next of kin. Consent was obtained for all residents before randomisation to minimise selection bias. ${ }^{24}$ Pre-intervention assessments were completed before randomisation.

A cluster randomised controlled design was used to randomly allocate care homes to either the intervention arm or the control arm. Randomisation was performed by an independent principal statistician who used a computer generated randomisation list. Treatment arm was revealed to the treating therapists only, thereby ensuring that allocation was concealed from the independent assessors responsible for all subsequent assessments.

Residents in the intervention arm received a three month physiotherapy and occupational therapy intervention, whereas those in the control arm received standard care. The physiotherapy intervention was developed using a modified version of the protocol detailed by O'Neil and colleagues and the consensus of a steering group of expert physiotherapists. ${ }^{25}$ Therapy was aimed at enhancing mobility and the ability to perform activities of daily living independently, and addressed components such as strength, flexibility, balance, and exercise tolerance. In addition, functional tasks such as bed to chair transfers, sit to stand, and walking or wheeling were practised. The intervention was delivered by two qualified physiotherapists and

Table 1|Characteristics of care homes recruited to the study compared with all homes meeting eligibility criteria in south Birmingham

Sample $(n=24) \quad$ All homes $(n=77)$

Number of homes by sector ( $\mathrm{n}(\%)$ )

\begin{tabular}{|c|c|c|}
\hline Private & $18(75)$ & $51(66)$ \\
\hline Voluntary & $3(13)$ & $10(13)$ \\
\hline Local authority & $1(4)$ & $13(17)$ \\
\hline Housing association & $2(8)$ & $3(4)$ \\
\hline \multicolumn{3}{|c|}{ Number of homes by type of care (n (\%)) } \\
\hline Nursing & $8(33)$ & $20(26)$ \\
\hline Residential & $16(67)$ & $57(74)$ \\
\hline $\begin{array}{l}\text { Number of beds (median (min, } \\
\text { max)) }\end{array}$ & $35(11,76)$ & $28(7,76)$ \\
\hline
\end{tabular}


Assessed for eligibility (77 homes)

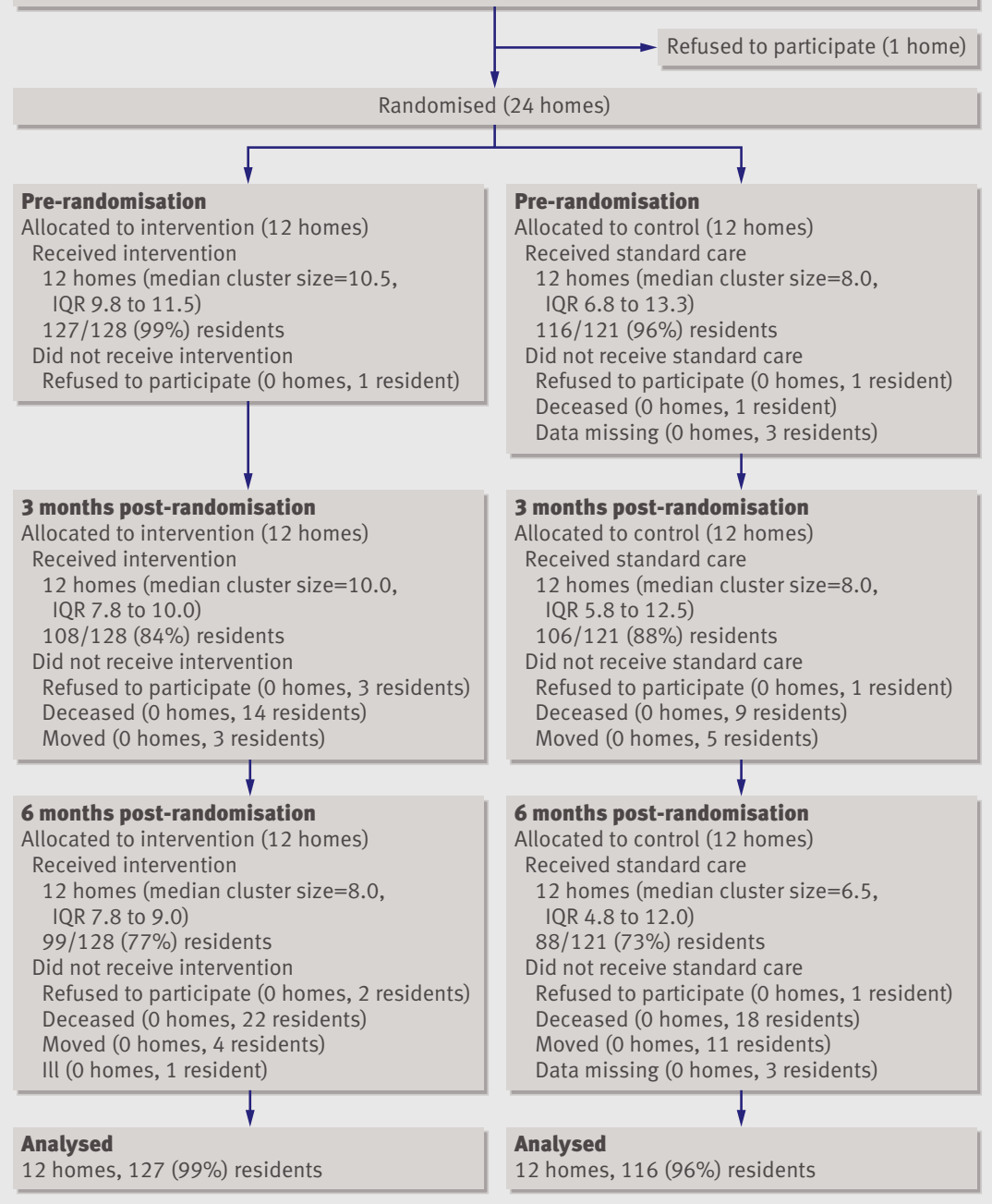

Fig 1 | CONSORT diagram. IQR, interquartile range

was adjusted for each individual to take into account their degree of ability. The level of treatment was based on an initial interview and assessment designed to establish individuals' physical and functional status and equipment needs.

The occupational therapy intervention was developed using the consensus of an occupational therapy steering group (as described by Sackley et al). ${ }^{26}$ Therapy was targeted towards improving independence in personal activities of daily living such as feeding, dressing, toileting, bathing, and transferring (for example, from bed to chair). The intervention was delivered by two qualified occupational therapists who followed a client centred approach, including routine assessment, treatment, and reassessment. The dose, frequency, and duration of both physiotherapy and occupational therapy were dependent on the goals agreed by the individual participant and the therapists and on progress throughout the intervention.

The intervention arm also included an intervention delivered to the care home staff. ${ }^{27}$ This involved a programme of staff training to provide practice in promoting residents' independence and the use of therapeutic aids. ${ }^{28}$

Residents in care homes allocated to the control arm continued to receive standard care equal to that received before recruitment to the trial. Occupational therapy was not used routinely by any of the homes and physiotherapy was accessed only via general practitioner referral. None of the homes had an identified person with specific responsibility for mobility, training for activities of daily living, or the provision of adaptive equipment. The control group received the therapy intervention after the trial had ended.

\section{Outcome measures}

Assessments were carried out by two independent assessors blinded to cluster allocation throughout the trial. Assessments were conducted before randomisation (baseline, between July 2004 and July 2005), at three months after randomisation (that is, at treatment completion for the intervention group; between October 2004 and October 2005), and at six months after randomisation (three month follow-up, between January 2005 and January 2006). The primary outcomes were the scores on the Barthel index and the Rivermead mobility index..$^{29}$ Measures of activities of daily living and of mobility were also selected as main outcomes because the intervention was targeted at a population in whom limitations in these parameters are highly prevalent.

In addition, the mini mental state examination was used at the first assessment to determine the level of residents' cognitive impairment (not an exclusion criterion). ${ }^{30}$ Residents categorised as cognitively impaired (that is, those who scored less than 24 on the mini mental state examination) had their principal carer act as a proxy when completing subsequent primary outcome measures.

The timed "up \& go" test was used to give a physical measure of mobility to support the primary measures. ${ }^{31} \mathrm{We}$ also anticipated that this test might highlight any false reporting by participants or carers on the primary measures.

Mood was assessed using the hospital anxiety and depression scale depression subscale. ${ }^{32}$ Residents unable to complete the hospital anxiety and depression scale for reasons such as cognitive impairment and illness had the stroke aphasic depression questionnaire completed by a proxy. ${ }^{33}$ Medical history and comorbidity information were also collected.

\section{Data analysis}

This study was powered according to information from a pilot study, ${ }^{13}$ which used an intracluster correlation of 0.18 and a standard deviation of 4 units to detect a difference of 2 units on the Barthel index at a significance level of $5 \%$ (80\% power). A 2 point change on the Barthel index was thought to be a meaningful change in independence with respect to activities of daily living. A sample size of 300 was targeted to allow for participant withdrawal. 
A detailed statistical analysis plan was developed prospectively in accordance with the extended CONSORT statement including cluster randomised trials. ${ }^{3435}$ Primary analyses for the Barthel index and Rivermead mobility index were conducted in accordance with the intention to treat principle and used all data recorded pre-randomisation, three months post-randomisation, and six months post-randomisation. The analyses were carried out by a statistician who was masked to group allocation, using SAS 9.1. Scores for the Barthel index and the Rivermead mobility index were summarised by treatment arm at each of the three assessments. Mean values and 95\% confidence intervals were calculated, although confidence intervals were not adjusted for clustering. Analyses were conducted on individual data at a $5 \%$ level of significance.

Separate multilevel models were used to test the efficacy of the intervention according to Barthel index score and Rivermead mobility index score using responses at three months post-randomisation and six months post-randomisation. Respective centred pre-intervention scores were included in the model as a covariate. ${ }^{3637}$ Assessment was defined as a

Table 2 | Baseline characteristics of care homes and participants by study group

\begin{tabular}{|c|c|c|c|}
\hline & \multicolumn{2}{|c|}{ Study group } & \multirow[b]{2}{*}{ Combined } \\
\hline & Intervention & Control & \\
\hline \multicolumn{4}{|c|}{ Care home factors at baseline } \\
\hline Number of care homes & 12 & 12 & 24 \\
\hline Median cluster size & 10.5 & 8.0 & 10 \\
\hline Interquartile range & 9.8 to 11.5 & 6.8 to 13.3 & 7.5 to 13.0 \\
\hline
\end{tabular}

\section{Resident factors at baseline}

\begin{tabular}{lccc}
\hline Number of residents & 128 & 121 & 249 \\
\hline Age (years; mean (SD)) & $86(7)$ & $84(10)$ & $85(9)$ \\
\hline Female ( $(\%))$ & $101(79)$ & $84(69)$ & $185(74)$ \\
\hline $\begin{array}{l}\text { At least one confirmed stroke }(\mathrm{n} \\
(\%)\end{array}$ & $28(22)$ & $26(21)$ & $54(22)$
\end{tabular}

(\%))

Mini mental state examination score (n (\%))

\begin{tabular}{lccc}
\hline$\ll 21$ & $91(71)$ & $77(64)$ & $168(67)$ \\
\hline $21-23$ & $5(4)$ & $16(13)$ & $21(8)$ \\
\hline 124 & $32(25)$ & $28(23)$ & $60(24)$ \\
\hline
\end{tabular}

Hospital anxiety and depression scale (anxiety subscale) score ( $(\%))$

\begin{tabular}{lccc}
\hline Hospital anxiety and depression scale (anxiety subscale) score $(\mathrm{n}(\%))$ & \\
\hline $0-7$ & $42(33)$ & $49(40)$ & $91(37)$ \\
\hline $8-10$ & $7(5)$ & $9(7)$ & $16(6)$ \\
\hline $11-21$ & $6(5)$ & $7(6)$ & $13(5)$
\end{tabular}

Hospital anxiety and depression scale (depression subscale) score (n (\%))

\begin{tabular}{lccc}
\hline $0-7$ & $44(35)$ & $55(45)$ & $99(39)$ \\
\hline $8-10$ & $7(5)$ & $7(6)$ & $14(6)$ \\
\hline $11-21$ & $4(3)$ & $3(2)$ & $7(3)$ \\
\hline
\end{tabular}

Stroke aphasic depression questionnaire score (n (\%))

\begin{tabular}{lccc}
\hline$\ll 14$ & $16(12)$ & $6(5)$ & $22(9)$ \\
\hline$\geq 14$ & $52(41)$ & $37(31)$ & $89(36)$ \\
\hline Emotional distress & $56(44)$ & $40(33)$ & $96(39)$ \\
\hline Data missing (n (\%)) & & & \\
\hline $\begin{array}{l}\text { Did not complete HADS or } \\
\text { SADQ }\end{array}$ & $5(4)$ & $13(11)$ & $18(7)$
\end{tabular}

Mini mental state examination: 〈21 cognitive impairment; $21-23$ borderline; >24 cognitively sound. Hospital anxiety and depression scale (HADS): 0-7 normal; 8-10 borderline; 11-21 abnormal. Stroke aphasic depression questionnaire (SADQ): $\geq 14$ depressed; $<14$ not depressed. Emotional distress: combines participants categorised as depressed on the SADQ and the HADS depression subscale. repeated measures factor. Study group, assessment (three months post-randomisation and six months post-randomisation), and interaction between the two were modelled as fixed effects. Care home and participants were modelled as random effects. Models with different error structures were fitted. ${ }^{37}$ Estimated effects and 95\% confidence intervals are reported from the model of best fit.

Sensitivity analyses (using the same multilevel models) were conducted on Barthel index and Rivermead mobility index scores. Data were used from all participants who were assessed before randomisation and missing data were imputed through three mechanisms (best case scenario, worst case scenario, and missing mechanism). A further analysis was conducted using a complete data set (data from participants who provided data pre-intervention and were not protocol violators). No contradictory findings were found; therefore, only primary analyses have been reported in the results section.

A further analysis was conducted using separate multilevel models to test time standardised area under the curve values for Barthel index and Rivermead mobility index scores across follow-up assessments. Respective centred pre-intervention scores were included in the model as a covariate, study group was modelled as a fixed effect, and care home and participants were modelled as random effects. The same error structure was used as in the "best fit" model above. Estimated intervention effects and 95\% confidence intervals are reported. The estimated value for the intracluster correlation coefficient was computed using pre-intervention scores on the Barthel index and the Rivermead mobility index.

\section{RESULTS}

\section{Participants}

A total of 24 homes and 249 participants were recruited to the trial. Twelve homes were randomised to each group, with 128 residents allocated to the intervention arm (median number per home $=11$ ) and 121 to the control arm (median number per home $=8$ ). Before the intervention started, six participants (one in the intervention group and five in the control group) had withdrawn from the study. This number increased to 35 by the time of the three month follow-up (20 in the intervention group and 15 in the control group), and 62 by the time of the six month follow-up ( 29 in the intervention group and 33 in the control group). Reasons for withdrawal are depicted in the consort diagram in fig 1 .

Table 2 indicates participant demographics including age, gender, proportion of participants with confirmed stroke, level of cognitive impairment, and proportion of participants with a mood disorder.

\section{Comorbidities}

Comorbidities of the 249 residents who participated in the study were recorded and grouped into categories according to comorbidity type. The majority of comorbidities were musculoskeletal problems $(57 \%$ of 

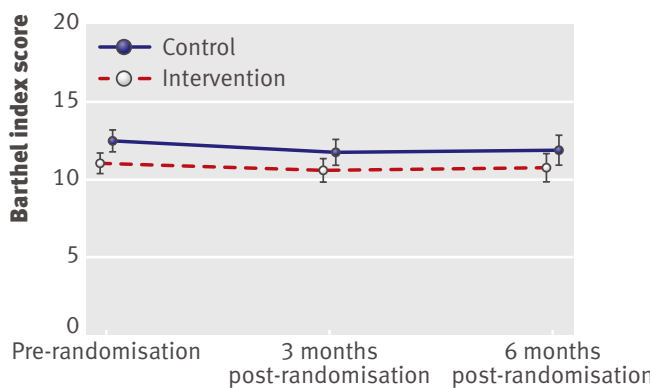

Intervention 127

106

108

88

99

Fig 2 | Barthel index scores across groups and assessments (responders). The mean Barthel index scores for participants in the intervention group did not change notably over time and were not significantly different from those of participants in the control group

residents). Cardiovascular (23\%), digestive (25\%), and nervous system $(30 \%)$ comorbidities were also common, as was stroke $(24 \%)$, which was categorised independently. The most common specific comorbidities were arthritis $(56 \%)$, stroke $(46 \%)$, dementia (40\%), and diabetes $(36 \%)$.

\section{Intervention}

Tables 3 and 4 indicate the different categories within the physiotherapy and occupational therapy portions of the intervention, the total proportion of treatment time spent working on each category, and components within categories.

Out of 128 participants randomised, 123 received physiotherapy and occupational therapy to some degree. The mean number of physiotherapist visits was 6.4 per resident, with an average total contact time of 2.21 hours per resident. The mean number of occupational therapist visits was 9.8 per resident, with an average total contact time of 3.6 hours per resident.

No serious adverse events were observed in any of the clusters as a result of the intervention or assessments.

\section{Primary analyses}

Primary analyses were conducted on responses from 243 participants who completed pre-randomisation measures: 127 in the intervention group and 116 in the control group. Overall, participants exhibited a low level of independence before randomisation, with mean Barthel index scores of 11.1 and 12.5 in the intervention and control groups, respectively (table 5). Furthermore, very low levels of mobility were evident pre-randomisation, with mean Rivermead mobility index scores of 5.8 and 6.9 in the intervention and control groups, respectively (table 4).

No statistically significant differences were found between the study groups on mean scores for Barthel index or Rivermead mobility index (adjusting for clusters) at either three months post-randomisation or six months post-randomisation.
Intracluster correlation coefficient values of 0.49 and 0.48 were calculated using pre-intervention scores on Barthel index and Rivermead mobility index, respectively.

Once adjusted for home effect and pre-intervention scores, none of the differences in mean Barthel index scores between study groups at six months post-randomisation follow-up reached the minimal important difference threshold of 2 index points (mean effect $0.08,95 \%$ confidence interval -1.14 to 1.30; $\mathrm{P}$ value $=0.90$, table 6 ). Likewise, the minimal important difference value of 2 index points was not reached for the differences in mean Barthel index scores across assessments (mean effect $-0.01,-0.63$ to 0.60 ; $\mathrm{P}=0.96$ ) or for the interaction between intervention and assessment (mean effect $0.42,-0.48$ to 1.32 ; $\mathrm{P}=0.36)$. No differences were statistically significant.

Once adjusted for home effect and pre-intervention scores, the minimal important difference threshold of 3 index points was not reached for mean Rivermead mobility index scores at six months post-randomisation across study groups (mean effect $0.62,95 \%$ confidence interval -0.51 to $1.76 ; \mathrm{P}=0.28$ ), across assessments (mean effect $-0.15,-0.65$ to 0.35 ; $\mathrm{P}=0.55)$, or for the interaction between intervention and assessment (mean effect $0.71,-0.02$ to 1.44 ; $\mathrm{P}=0.06) .{ }^{38}$ No differences were statistically significant.

Table 3|Proportion of treatment time spent on each component of the physiotherapy portion of the intervention

Proportion of total treatment time (\%)

\begin{tabular}{|c|c|}
\hline Assessments & 45.42 \\
\hline Initial interview & 25.98 \\
\hline Review & 17.54 \\
\hline Goal setting & 0.67 \\
\hline Other & 1.23 \\
\hline Mobility and transfers & 30.28 \\
\hline Bed mobility & 0.52 \\
\hline Transfers & 14.14 \\
\hline Standing & 3.93 \\
\hline Walking & 10.98 \\
\hline Other & 0.71 \\
\hline Impairment & 17.98 \\
\hline Strength & 6.40 \\
\hline Balance & 3.77 \\
\hline Flexibility & 4.61 \\
\hline Endurance & 0.15 \\
\hline Group exercise & 1.41 \\
\hline Other & 1.64 \\
\hline Equipment & 0.37 \\
\hline Ambulation/orthopaedic aid & 0.37 \\
\hline Communication & 5.95 \\
\hline Referrals & 0.31 \\
\hline Liaison & 3.47 \\
\hline Caregiver education & 0.36 \\
\hline Resident education and techniques & 1.81 \\
\hline TOTAL & 100 \\
\hline
\end{tabular}


Table $4 \mid$ Proportion of treatment time spent on each component of the occupational therapy portion of the intervention

Proportion of total

treatment time (\%)

\begin{tabular}{lc} 
Mobility and activities of daily living & 41.14 \\
\hline Transfers and mobility & 27.60 \\
\hline Group exercises & 7.75 \\
\hline Activities of daily living training & 5.79 \\
\hline Assessments & 35.75 \\
\hline Initial interview & 21.89 \\
\hline Review & 12.59 \\
\hline Goal setting & 1.27 \\
\hline Adaptations & 12.41 \\
\hline Adaptive equipment & 8.30 \\
\hline Wheelchairs and seating & 2.9 \\
\hline Environmental adaptations & 1.21 \\
\hline Communication & 9.02 \\
\hline Referrals & 4.08 \\
\hline Liaisons & 3.02 \\
\hline Information & 1.19 \\
\hline Caregiver training & 0.38 \\
\hline Resident education and techniques & 0.35 \\
\hline Other & 1.68 \\
\hline TOTAL & 100 \\
\hline
\end{tabular}

Profile plots of mean Barthel index scores (fig 2) and mean Rivermead mobility index scores (fig 3) for participants at any assessment show that the intervention did not improve the scores of the treatment group over those of the control group.

In analyses on area under the curve values, no significant differences were found across study groups on Barthel index score (mean effect 0.54, 95\% confidence interval -0.69 to $1.77 ; \mathrm{P}=0.37$ ) or Rivermead mobility index score (mean effect $1.11,-0.14$ to $2.36 ; \mathrm{P}=0.078$; table 6).

The results of the timed "up \& go" test were not analysed as this outcome was found to be inappropriate for use in our study population. The very large amounts of missing data for this variable and the huge variation in times among participants who did complete the measure meant it was not possible to analyse and draw any meaningful conclusion from the data.

\section{DISCUSSION}

The results of our study suggest that the three month occupational therapy and physiotherapy programme was not effective in promoting independent living and mobility among care home residents over and above that achieved with standard care.

The intervention was based on "best practice" approaches developed according to clinical evidence and expert views. Evidence exists to support occupational therapy and particular aspects of physiotherapy after stroke, but little evidence is available to support more widespread use of physiotherapy and occupational therapy. ${ }^{39}$ Much of the practice of occupational therapy and physiotherapy is not evidence based, however, or even theory based, but has developed through practice and opinion. One could, therefore, argue that the absence of positive findings in our study could be because the intervention was inappropriate for the target group, thus resulting in no measurable benefits. The intervention dose varied between individuals as it was dependent on participants' and therapists' agreed goals and on progress throughout the intervention period. A different dose could potentially be more beneficial.

\section{Comparison with other studies}

Previous studies of physiotherapy and occupational therapy in this setting provide conflicting results. ${ }^{15-20}$ Results of this trial, however, seem to support those of the studies mentioned previously, which concluded that similar functional rehabilitation interventions had minimal impact on elderly people in residential care. ${ }^{10-13}$

\section{Limitations}

Certain characteristics of the population were unexpected, which could suggest that a larger sample is required. The intracluster correlation coefficients of 0.49 and 0.48 for the Barthel index and Rivermead mobility index, respectively, were higher than was anticipated from the sample size calculation conducted; however, similar intracluster correlation coefficients were observed in a study with participants from a similar population. ${ }^{40}$ In addition, an analysis of a large number of studies that used intracluster correlation coefficients concluded that the magnitude of between cluster variation for a given measure can rarely be estimated in advance. ${ }^{41}$

In this study, care home residents were included in the trial if they scored in the mid-range on the Barthel index. It is worth noting that initial Barthel index screening was carried out by care home staff, and some residents did not score within the inclusion parameters when subsequent baseline assessments were done. We decided that these residents should remain in the trial. The inclusion of these residents could pos-

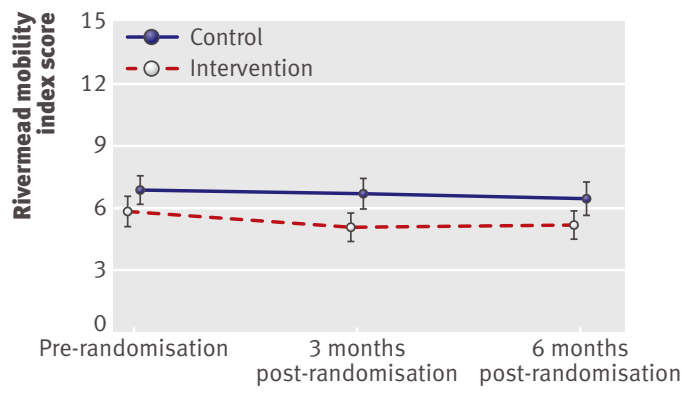

$\begin{array}{llll}\text { Control } & 113 & 106 & 88 \\ \text { Intervention } & 127 & 107 & 98\end{array}$

Fig 3 | Rivermead mobility index scores across groups and assessments (responders). The mean Rivermead mobility index scores for participants in the intervention group did not change notably over time and were not significantly different from those of participants in the control group. 
Table 5 | Summary statistics of Barthel index and Rivermead mobility index scores

\begin{tabular}{|c|c|c|c|c|}
\hline & \multicolumn{4}{|c|}{ Study group } \\
\hline & \multicolumn{2}{|c|}{ Intervention } & \multicolumn{2}{|r|}{ Control } \\
\hline & $\mathrm{n}$ & Mean $(95 \% \mathrm{Cl})$ & $\mathrm{n}$ & Mean $(95 \% \mathrm{Cl})$ \\
\hline \multicolumn{5}{|l|}{ Barthel index score } \\
\hline Pre-randomisation & 127 & 11.1 (10.4 to 11.9$)$ & 116 & 12.5 (11.7 to 13.2$)$ \\
\hline $\begin{array}{l}3 \text { months post- } \\
\text { randomisation }\end{array}$ & 108 & $10.6(9.8$ to 11.4$)$ & 106 & 11.8 (10.9 to 12.6$)$ \\
\hline $\begin{array}{l}6 \text { months post- } \\
\text { randomisation }\end{array}$ & 99 & 10.7 (9.8 to 11.6$)$ & 88 & 11.9 (10.9 to 12.9$)$ \\
\hline \multicolumn{5}{|c|}{ Rivermead mobility index score } \\
\hline Pre-randomisation & 127 & 5.8 (5.1 to 6.5$)$ & 113 & 6.9 (6.2 to 7.5$)$ \\
\hline $\begin{array}{l}3 \text { months post- } \\
\text { randomisation }\end{array}$ & 107 & 5.1 (4.4 to 5.8$)$ & 106 & 6.7 (6.0 to 7.5$)$ \\
\hline $\begin{array}{l}6 \text { months post- } \\
\text { randomisation }\end{array}$ & 98 & $5.2(4.5$ to 6.0$)$ & 88 & 6.5 (5.7 to 7.3$)$ \\
\hline
\end{tabular}

sibly have masked intervention benefits slightly because the intervention would be of insufficient intensity to be beneficial in these individuals.

Another limitation is the absence of physical performance data. The timed "up \& go" test was used as an outcome measure; however, the majority of participants were unable to complete the task, thus precluding analyses on this outcome. Other research suggests that an inability to complete the timed "up \& go" test is associated with poor health and mortality. ${ }^{42}$

The study could also be criticised because all residents with the defined level of dependency were referred for physiotherapy and/or occupational therapy, yet in routine clinical practice only those with a specific problem would be referred. Essentially, the therapists were in some cases delivering interventions that maintained the physical abilities of the residents rather than actively rehabilitated them. In addition, it could be argued that the setting of this study does not lend itself to improvements in independence that could be recorded with the outcome measures selected because of the standard institutional risk policies in place. It could potentially be difficult to improve independence in an environment where policies require residents to be assisted in certain activities, whether they are capable or not. For example, nearly all

Table 6 |Summary of effects at six months post-randomisation in the multilevel model for Barthel index and Rivermead mobility index, adjusted for home effect and pre-intervention scores

\begin{tabular}{|c|c|c|c|c|}
\hline & \multicolumn{4}{|c|}{ Outcome measure } \\
\hline & \multicolumn{2}{|c|}{ Barthel index } & \multicolumn{2}{|c|}{ Rivermead mobility index } \\
\hline & Estimate $(95 \% \mathrm{Cl})$ & $P$ value & Estimate $(95 \% \mathrm{Cl})$ & $P$ value \\
\hline \multicolumn{5}{|c|}{ Repeated measures analysis } \\
\hline Intervention & $0.08(-1.14$ to 1.30$)$ & 0.90 & $0.62(-0.51$ to 1.76$)$ & 0.28 \\
\hline Assessment & $-0.01(-0.63$ to 0.60$)$ & 0.96 & $-0.15(-0.65$ to 0.35$)$ & 0.55 \\
\hline Interaction & $0.42(-0.48$ to 1.32$)$ & 0.36 & $0.71(-0.02$ to 1.44$)$ & 0.057 \\
\hline Covariate & 0.71 (0.59 to 0.83$)$ & $<0.0001$ & $0.61(0.50$ to 0.72$)$ & $<0.0001$ \\
\hline \multicolumn{5}{|c|}{ Area under the curve analysis } \\
\hline Intervention & $0.54(-0.69$ to 1.77$)$ & 0.37 & $1.11(-0.14$ to 2.36$)$ & 0.078 \\
\hline Covariate & $0.72(0.59$ to 0.84$)$ & $<0.0001$ & $0.60(0.49$ to 0.71$)$ & $<0.0001$ \\
\hline
\end{tabular}

homes have a policy of assisted bathing as this activity of daily living would involve a high risk of falls if done independently by this population.

\section{Future research}

Given that this area of research is relatively novel, the optimum intervention dose has yet to be established. Future research should investigate varying intensities and doses of therapies of this type. In addition, future studies could use a more selective approach to intervention delivery, as in practice only those individuals referred for therapy would receive such services. However, research has shown that care home staff often do not know when or who to refer for rehabilitation therapy. ${ }^{43}$ Thus, a careful selection process would need to be adopted to prevent the main objectives of such research being jeopardised.

This study was novel in that an observational measure of emotional distress was used for residents who scored less that 24 on the mini mental state examination. The levels of emotional distress recorded were much higher than predicted. Depression would certainly reduce the ability to engage in therapy and to retain any improvement and could, therefore, be a factor in the apparent lack of intervention benefit in this study. Future studies could analyse the different responses to therapy of individuals with varying levels of emotional distress.

\section{Other considerations}

One issue in care homes in the UK is the ability of staff to recognise which residents have maintenance or rehabilitation potential. One recent study found that stroke patients in nursing homes who were less likely to receive rehabilitation actually appeared to benefit more from therapy than did more typical candidates. ${ }^{19}$ There seems to be a need for nurses and care home staff to be better educated with regard to identifying rehabilitation potential in care home residents. ${ }^{43}$

\section{WHAT IS ALREADY KNOWN ON THIS TOPIC?}

Care home residents have greater dependence in activities of daily living than do community dwelling elderly people

Care home residents have limited access to physiotherapy and occupational therapy

Research is inconclusive as to whether such therapies are beneficial in this population and, subsequently, a cost effective service

\section{WHAT THIS STUDY ADDS}

The three month physiotherapy and occupational therapy intervention delivered did not prove more beneficial than standard care in this sample

The prevalence of mood disorders and cognitive impairment was greater than was previously anticipated

The findings do not to support the argument that such services would be cost effective and reduce burden on care staff and society 


\section{Conclusion}

The physiotherapy and occupational therapy intervention administered in this study resulted in no measurable improvements in functional independence and mobility. It may be hasty to conclude that physiotherapy and occupational therapy have absolutely no value in this population. From the outcomes of this study, however, one could conclude that these therapies do not have an effect on independence and mobility when applied relatively unselectively. In addition, it seems that the results do not support the provision of such services. Further research could investigate a concurrent intervention to address the apparent prevalence of mood disorders and cognitive impairment in this population. Until more conclusive findings are available, current practice and access to rehabilitation therapy services in this population are unlikely to change.

We acknowledge the help of care home residents and staff, the trial steering group chaired by Professor Marion Walker and including Professor Jonathan Mant, and the occupational therapy and physiotherapy advisory groups. We also thank Professors David Mant and Derick Wade for contributing to the study design. Finally, we would like to thank the locum therapists: Nicola Brittle, Eric Morgan, and Pam Versveldt.

Contributors: CMS was principal investigator and led the design, management, and writing up of the trial. TJH and KH were responsible for the coordination of the trial, the independent assessments, and data management. TJH also contributed to the design of the study and was responsible for writing up the trial for publication. CCW and SP were responsible for the development of the statistical analyses plans, conducting the analyses, and written presentation of the results. MEvdB and $\mathrm{KL}$ contributed to the design of the intervention protocol and administered the physiotherapy and occupational therapy components of the intervention, respectively.

Funding: This study was funded by the Health Foundation and the NHS National Institute for Health Research. The University of Birmingham acted as sponsors. The funders and sponsor had no involvement in the study design, data collection, analysis and interpretation, the writing of the report, or the decision to submit the paper for publication.

Competing interests: None declared.

Ethical approval: Ethical approval was granted by the Oxfordshire Applied and Qualitative Research Ethics Committee. Further site specific approval was granted by the NHS South Birmingham and NHS Birmingham East and North Local Research Ethics Committees.

Data sharing: All authors had access to all the data in the trial and can take responsibility for the integrity of the data and the accuracy of the data analysis.

1 Barodawala S, Kesavan S, Young J. A survey of physiotherapy and occupational therapy provision in UK nursing homes. Clin Rehabil 2001;15:607-10.

2 De Boer ME, Leemrijse CJ, Van Den Ende CH, Ribbe MW, Dekker J. The availability of allied health care in nursing homes. Disabil Rehabil 2007;29:665-60.

3 Leemrijse CJ, de Boer ME, van den Ende CH, Ribbe MW, Dekker J. Factors associated with physiotherapy provision in a population of elderly nursing home residents; a cross sectional study. BMC Geriatr 2007;7:7.

4 Berg K, Sherwood S, Murphy K, Carpenter GI, Gilgen R, Phillips CD. Rehabilitation in nursing homes: a cross-national comparison of recipients. Age Ageing 1997;26(suppl 2):37-42S.

5 Buchanan RJ, Wang S, Martin RA, Ju H. Utilization of rehabilitation therapies by nursing home residents with MS at admission. NeuroRehabilitation 2006;21:223-32.

6 Chiodo LK, Gerety MB, Mulrow CD, Rhodes MC, Tuley MR. The impac of physical therapy on nursing home patient outcomes. Phys Ther 1992;72:168-75.

7 Brill PA, Drimmer AM, Morgan LA, Gordon NF. The feasibility of conducting strength and flexibility programs for elderly nursing home residents with dementia. Gerontologist 1995;35:263-6.
8 Heyn P, Abreu BC, Ottenbacher KJ. The effects of exercise training on elderly persons with cognitive impairment and dementia: a metaanalysis. Arch Phys Med Rehabil 2004;85:1694-704.

9 Przybylski BR, Dumont ED, Watkins ME, Warren SA, Beaulne AP, Lier DA. Outcomes of enhanced physical and occupational therapy service in a nursing home setting. Arch Phys Med Rehabil 1996;77:554-61.

10 Schnelle JF, Alessi CA, Simmons SF, Al-Samarrai NR, Beck JC, Ouslander JG. Translating clinical research into practice: a randomized controlled trial of exercise and incontinence care with nursing home residents. J Am Geriatr Soc 2002;50:1476-83.

11 Schnelle JF, Cruise PA, Rahman A, Ouslander JG. Developing rehabilitative behavioural interventions for long-term care: technology transfer, acceptance and maintenance issues. J Am Geriatr Soc 1998;46:771-7.

12 Shaw C, Williams KS, Assassa RP. Patients' views of a new nurse-led continence service. J Clin Nurs 2000;9:574-82.

13 Edwards H, Chapman H, Forster E, Gaskill D, Morrison P, Sanders F. Challenges associated with implementing an education program in a residential aged care setting. Aust Health Rev 2003;26:107-15.

14 Irwin B, Patterson A, Boag P, Power M. Management of urinary incontinence in a UK trust. Nurs Stand 2001;16:33-7.

15 Kerse N, Peri K, Robinson E, Wilkinson T, von Randow M, Kiata L, et al. Does a functional activity programme improve function, quality of life, and falls for residents in long term care? Cluster randomised controlled trial. $B M J$ 2008;337:a1445.

16 Mozley CG, Schneider J, Cordingley L, Molineux M, Duggan S, Hart C, et al. The care home activity project: does introducing an occupational therapy programme reduce depression in care homes? Aging Ment Health 2007;11:99-107.

17 Mulrow CD, Gerety MB, Kanten D, Cornell JE, DeNino LA, Chiodo L, et al. A randomized trial of physical rehabilitation for very frail nursing home residents. JAMA 1994;271:519-24.

18 Sackley CM, Wade DT, Mant D, Copley Atkinson J, Yudkin P, Cardoso K, et al. Cluster randomized pilot controlled trial of an occupational therapy intervention for residents with stroke in UK care homes. Stroke 2006;37:2336-21.

19 Rydwik E, Frandin K, Akner G. Effects of physical training on physical performance in institutionalised elderly patients (70+) with multiple diagnoses. Age Ageing 2004;33:13-23.

20 Helbostad JL. Fysisk trening av sykehjemsbeboere - har det noen hensikt? [Physical training for nursing home residents-has it any effect?] Tidsskr Nor Laegeforen 2005 4;125:1195-7 [Norwegian].

21 Schnelle JF, Kapur K, Alessi C, Osterweil D, Beck JG, Al Samarrai NR, et al. Does an exercise and incontinence intervention save healthcare costs in a nursing home population? J Am Geriatr Soc 2003;51:161-8.

22 Ouslander JG, Griffiths P, McConnell E, Riolo L, Schnelle J. Functional incidental training: applicability and feasibility in the Veterans Affair nursing home patient population. J Am Med Dir Assoc 2005;6:121-7.

23 Collin C, Wade DT, Davies S, Horne V. The Barthel ADL Index: a reliability study. Int Disabil Stud 1988;10:61-3.

24 Puffer S, Torgerson D, Watson J. Evidence for risk of bias in cluster randomised trials: review of recent trials published in three general medical journals. BMJ 2003;327:785-9.

25 O’Neil MB, Woodard M, Sosa V, Hunter L, Mulrow CD, Gerety MB, et al. Physical therapy assessment and treatment protocol for nursing home residents. Phys Ther 1992;72:596-604.

26 Sackley CM, Atkinson JC, Walker MF. Occupational therapy in nursing and residential care settings: a description of a randomised controlled trial intervention. Br J Occupat Ther 2004;67:104-10.

27 Paterson M, Higgs J, Wilcox S. The artistry of judgement: a model fo occupational therapy practice. Br J Occupat Ther 2005;68:409-17.

28 Van den Berg MEL, Lett K, Sackley CM. Maintaining residents' mobility and activity: a workshop for care home staff. Nurs Times 2006;102:32-4

29 Collen FM, Wade DT, Robb GF, Bradshaw CM. The Rivermead Mobility Index: a further development of the Rivermead Motor Assessment. Int Disabil Stud 1991;13:50-4.

30 Folstein MF, Folstein SE, McHugh PR. Mini-mental state: a practical method for grading the cognitive state of patients for the clinician. Psychiatr Res 1975;12:189-98.

31 Podsiadlo D and Richardson S. The timed "Up \& Go": a test of basic functional mobility for frail elderly persons. J Am Geriatr Soc 1991;39:142-8.

32 Zigmund AS, Snaith RP. The Hospital and Anxiety Depression Scale. Acta Psych Scand 1983;67:261-70.

33 Sutcliffe LM, Lincoln NB. The assessment of depression in aphasic stroke patients: the development of the Stroke Aphasic Depression Questionnaire. Clin Rehabil 1998;12:506. 
34 Moher D, Shultz KF, Altman DG. The CONSORT statement: revised recommendations for improving the quality of reports of parallelgroup randomised trials. Lancet 2001;357:1191-4.

35 Campbell MK, Elbourne DR, Altman DG. CONSORT statement: extension to cluster randomised trials. BMJ 2004;328:702-8.

36 Donner A, Klar N. Design and analysis of cluster randomization trial in health research. Arnold, 2000.

37 Laird NM, Donnelly C, Ware HW. Longitudinal studies with continuous responses. Stat Methods Med Res 1992;1:225-47.

38 Green J, Forster A, Young J. A test-retest reliability study of the Barthel Index, the Rivermead Mobility Index, the Nottingham Extended Activities of Daily Living Scale and the Frenchay Activities Index in stroke patients. Disabil Rehabil 2001;23:670-6.

39 Legg L, Drummond A, Leonardi-Bee J, Gladman JRF, Corr S, Donkervoort $M$, et al. Occupational therapy for patients with problems in personal activities of daily living after stroke: systematic review of randomised trials. BMJ 2007;335:922-5.
40 Sackley CM, Rodriguez NA, Badger F, Wright CC, van den Berg MEL, Besemer J, et al. A phase II exploratory cluster randomised controlled trial of a group mobility training and staff education intervention to promote urinary continence in UK care homes. Clin Rehabil 2008;22:714-21.

41 Adams G, Gulliford MC, Ukoumunne OC, Eldridge S, Chinn S, Campbell MJ. Patterns of intra-cluster correlation from primary care research to inform study design and analysis. J Clin Epidemiol 2004;57:785-94.

42 Rockwood K, Jones D, Wang Y, Carver D, Mitnitski A. Failure to complete performance-based measures is associated with poor health status and an increased risk of death. Age Ageing 2007;36:225-8.

43 Murray PK, Dawson NV, Thomas CL, Cebul RD. Are we selecting the right patients for stroke rehabilitation in nursing homes? Arch Phys Med Rehabil 2005;86:876-80.

Accepted: 1 March 2009 